\title{
El debate sobre el PARLASUR en los medios de comunicación de Argentina: dos perspectivas de un mismo fenómeno
}

\section{Brenda Luciana Maffei}

\begin{abstract}
Advogada pela Faculdade de Direito da Universidade de Buenos Aires. Mestre pela Faculdade de Direito da Universidade Federal de Rio Grande do Sul (UFRGS) (Bolsista CAPES). Doutoranda pelo Programa de pós-graduação da Universidade Federal de Santa Catarina (UFSC) (Bolsista CAPES PEC-PG). Contato: brenda_maffei@yahoo.com.ar. Lattes: http://lattes.cnpq.br/0814079878860165.
\end{abstract}

\section{Resumo}

Com a sanção da lei 27.120 de dezembro de 2014, promulgada no dia 6 de janeiro de 2015, na qual se institui a obrigação para os cidadãos argentinos da eleição direta dos parlamentários do Parlamento do MERCOSUL (Parlasul), iniciou-se um debate mediático na República Argentina que demonstra a existência de duas posturas díspares. Entre essas duas posturas estão, por um lado, aqueles que sustentam que o Parlasul é um órgão relevante para o desenvolvimento do processo de integração e, pelo outro, os que argumentam que é um órgão desnecessário e pouco funcional. Partindo das premissas de que mídia configura um elemento fundamental na conformação da opinião pública, o objetivo centra deste trabalho é analisar criticamente a forma como dois jornais (Clarín e Página12) apresentaram a questão parlamentária do MERCOSUR, especialmente a partir do envio do projeto de lei ao Congresso Nacional, que institui as eleições diretas. Os discursos elaborados desde estes dois jornais são um exemplo das duas posturas mencionadas antes. Além disso, por ser o Parlasul um órgão destinado à representação dos cidadãos do bloco regional, a ideia que os próprios cidadãos se formem sobre ele é parte fundamental da análise.

Palavras-chave: Mídia; Opinião Pública; Parlasul.

\begin{abstract}
With the adoption of the law 27,120 on December 29, 2014, published on January 6, 2015, in which the obligation for the Argentine citizens to directly elect parliamentarians of the Mercosur Parliament (Parlasur) is instituted, a discussion has been starts on Argentinian media, that demonstrates the existence of two disparate positions. Between these two positions are, on the one hand, those who argue that the Parlasur is a relevant organ to the development of the integration process and, on the other hand, those who argue that it is an unnecessary and dysfunctional body. Starting from the premise that the media forms a key element in shaping public opinion, the main objective of this paper is to critically analyze how two newspapers (Clarín and Página 12) presented a parliamentary question within MERCOSUR. The different discourses made by these two newspapers are an example of the two positions mentioned above. In addition, as the Parlasur is a relatively new body, which represents the citizens of the regional block, the idea that citizens themselves are formed on it is a fundamental part in the analysis. In the conformation of this idea, the media has a key role.
\end{abstract}

Keywords: Media; Public Opinion; Parlasur.

\section{Resumen}

Con la sanción de la ley 27.120 el 29 de diciembre de 2014, promulgada el 6 de enero de 2015, por la que se instituye la obligación a los ciudadanos argentinos de la elección directa de parlamentarios del Parlamento del Mercosur (Parlasur), se inició un debate mediático en la República Argentina que demuestra la existencia de dos posturas dispares. Entre esas dos posturas están, por un lado, aquellos que sostienen que el Parlasur es un órgano relevante para el desarrollo del proceso de integración y, por el otro, los que argumentan que es un órgano innecesario y poco funcional. Partiendo de las premisas de que los medios de comunicación configuran un elemento fundamental en la conformación de la opinión pública, el objetivo central de este trabajo es analizar críticamente la forma en que dos periódicos (Clarín y Página 12) presentaron la cuestión parlamentaria del MERCOSUR dentro de la Argentina, especialmente a partir del envío del proyecto de ley al Congreso Nacional que instituye las elecciones directas. Los discursos elaborados desde estos dos periódicos son un ejemplo de las dos posturas mencionadas anteriormente. Además, por ser el Parlasur un órgano destinado a la representación de los ciudadanos del bloque regional, la idea que los propios ciudadanos se formen sobre él es parte fundamental en el análisis. En este pensar, los medios de comunicación poseen un rol fundamental. 
Palabras clave: Medios de comunicación; Opinión pública; Parlasur.

\section{Introducción}

Con la sanción de la ley 27.120 el 29 de diciembre de 2014, promulgada el 6 de enero de 2015, por la que se instituye la obligación de la elección directa de parlamentarios del Parlamento del Mercosur (Parlasur), se inició un debate mediático en la República Argentina que demuestra la existencia de dos posturas dispares entre aquellos que sostienen que el Parlasur es un órgano relevante para el desarrollo del proceso de integración y aquellos que argumentan, por el contrario, que es un órgano innecesario y poco funcional.

Además de ese debate, la sanción de la ley, provocó, por un lado, que los partidos políticos comenzasen a discutir cuestiones regionales dentro de sus campañas electorales y, por otro, se inició una discusión sobre quienes serían los candidatos de los partidos políticos, cuáles serían los intereses envueltos en la elección directa de los parlamentarios, cuáles serían las reales funciones del Parlasur, etc. Lo anterior, de cara a las elecciones generales que se produjeron en octubre de 2015. Así, este debate refleja un fenómeno novedoso, donde por primera vez se discutieron asuntos relacionados con la dimensión parlamentaria del bloque, en general, y con el Parlasur, en particular, de una forma más intensa en los medios de comunicación argentinos, ya que las noticias que envolvieron cuestiones relativas al Parlasur aumentaron en términos cuantitativos de forma considerable a partir de la entrada en vigor de la mencionada ley.

Partiendo de las premisas de que los medios de comunicación son una parte importante en la conformación de la opinión pública, el objetivo central de este trabajo es analizar críticamente la forma en que dos periódicos (Clarín y Página 12), presentaron la cuestión parlamentaria del MERCOSUR dentro de la Argentina.

Para el objetivo expuesto, se tomarán como fuentes primarias a ser analizadas: 1) los documentos normativos relativos a la creación y funcionamiento del Parlasur, 2) las notas periodísticas de dos de los periódicos objeto de estudio. El periodo analizado abarca desde la creación del Parlasur en 2006, hasta las elecciones primarias en Argentina del 9 de agosto de 2015.

La metodología utilizada es el análisis lingüístico y crítico del discurso de esos dos medios, enfocándose, especialmente, en los debates que se iniciaron con el envío del proyecto de ley que instituye las elecciones directas en fines de 2014. El método utilizado analiza los signos de naturaleza lingüística, como por ejemplo editoriales, columnas de opinión, titulares, etc. (SANTANDER, 2011, p. 214).

Debe anticiparse, además, que escapa a los objetivos del presente estudio demostrar los efectos concretos que el debate y las diferentes opiniones en los principales periódicos produjeron efectivamente en la población argentina. En ese sentido, se reconoce la insuficiencia de este trabajo pues el mismo sólo se propone mostrar uno de los lados de esa relación, o sea, el lado del emisor, sin enfocarse de forma detallada en el receptor. Se deja planteada, así, la propuesta para la realización de un trabajo futuro que envuelva a todas las partes del vínculo: "medios de comunicación/ opinión pública”.

Es indudable que un trabajo de investigación del tipo propuesto no podrá indagar sobre la esfera mental y cognitiva de la ciudadanía, pero se parte de la idea que en la formación de ese 
pensar, los medios de comunicación tienen un rol fundamental. En este sentido, resulta interesante observar a quién o quiénes le dan voz los periódicos, para intentar identificar algunos de los posibles intereses que están envueltos en la selección y en la exposición de la noticia.

Llevando todo lo dicho anteriormente en consideración, se dice que la dimensión parlamentaria del MERCOSUR puede ser estudiada desde varias perspectivas. Desde un análisis que podría denominarse jurídico-institucional estático, el objeto analizable quedaría configurado por el Protocolo que dio origen al Parlasur estudiando, por ejemplo, sus objetivos, competencias, funciones, etc. Desde una perspectiva dinámica dentro de ese mismo análisis jurídico-institucional es posible estudiar cómo la práctica y el accionar de ese órgano coincide o no con lo que debería ser. No obstante, por ser el Parlasur un órgano destinado a la representación de los ciudadanos del bloque regional, la idea que los propios ciudadanos se formen sobre él es parte fundamental en el análisis. Esto quiere decir que no basta con analizar al Parlasur por lo que es y por lo que debería ser en términos jurídicos-institucionales, sino también, es necesario indagar sobre aquello que la propia ciudadanía piensa o podría llegar a pensar sobre él (opinión púbica) y, en este pensar, los medios de comunicación poseen un rol fundamental.

El trabajo está dividido en tres puntos. En el primer punto serán desarrollados, de forma breve, algunos conceptos relativos a la relación entre los medios de comunicación y la conformación de la opinión pública. A su vez, será expuesta la forma como esa relación se está dando en Argentina, principalmente, en el vínculo del actual gobierno y uno de los medios analizados, el Grupo Clarín. El segundo punto estudia la dimensión jurídico-institucional del Parlasur. En este punto se intentarán exponer las principales características y funciones del Parlasur y los debates jurídicos e institucionales que se suscitaron regionalmente e internamente desde la creación del mismo. En el último punto, central en este estudio, serán analizados y comparados los principales argumentos expuestos en dos de los principales periódicos de Argentina relacionado a la dimensión parlamentaria del MERCOSUR, especialmente, con relación al Parlasur y las elecciones directas establecidas por la ley 27.120 .

\section{Algunos datos sobre la relación medios de comunicación/opinión pública: el caso especifico de Argentina}

No caben dudas que los medios de comunicación ejercen un tipo de poder. En este sentido, forma parte del pensar popular que los medios de comunicación conformarían "el cuarto poder" (equiparándose éste a los otros tres poderes del Estado: Ejecutivo, Legislativo y Judicial). Evidentemente, desde un punto de vista técnico, esta afirmación no resulta ser verdadera. Sin embargo, si se entiende por poder una relación en la cual una persona o grupo de personas, una fuerza o una institución condicionan el comportamiento de otra u otras, con independencia de su voluntad o resistencia, $y$, asimismo, que la forma de ser ejercido ese poder no resulta ser siempre directa (como sería el caso de la coerción), los medios de comunicación podrían ajustarse a este concepto amplio de poder. En este orden de ideas, si fuera posible una categorización del poder del cual estamos hablando, el mismo se encontraría emparentado a lo ideológico. En este sentido, se entiende como tal, aquellos mecanismos utilizados para ejercer una coacción psicológica con el objetivo de hacer que determinada persona, o grupo de personas actúe de determinada forma y no de otra (CARPIZO, 1999, p.744).

Como fue mencionado en la introducción de este trabajo una de las herramientas de acceso 
a la información y de conocimiento de los actos gubernamentales y de los acontecimientos en general, tanto nacionales como internacionales es proporcionado por los medios de comunicación. En este sentido, más allá de la vivencia particular y de la experiencia inmediata de cada ciudadano, los medios informativos se presentan como "esas ventanas abiertas al inmenso mundo que queda más allá de nuestra experiencia directa, determinando los mapas cognitivos que nos hacemos de él" (RUBIO, 2009, p.4). No obstante, como también fuera adelantado en la introducción, los medios no se limitan a describir hechos de forma objetiva. Así, la subjetividad impera a la hora, no sólo de seleccionar aquello que será noticia, sino también, al incluir opiniones o escoger un determinado lenguaje y no otro. En este sentido, los medios de comunicación se colocan como uno de los factores determinantes de la formación de la opinión pública y, de esta forma, al mismo tiempo que muestran la realidad, también la crean.

Así, pueden identificarse a las tres funciones básicas de los medios de comunicación como: 1) la trasmisión de información; 2) moldeamiento y orientación de la opinión pública y 3) control del poder político (URIARTE, 2002, p. 347).

Dar una definición exacta de lo que se entiende por opinión pública no es una tarea fácil, por ser ésta una expresión confusa. Una de las formas para dar un significado sobre lo que se pretende explicar es, precisamente, indicando aquello que no es lo que se pretende explicar. Siguiendo esta lógica de exposición, la opinión pública no se confunde ni con la cultura, ni con las instituciones, ni con el conjunto de los paradigmas de ideas, creencias y valores que predominan en cada sociedad. Uriarte (2002), por ejemplo, separa lo que sería cultura política de aquello que puede ser considerado opinión pública. La primera, según él, se refiere a valores y actitudes profundas que indican un determinado tipo de relación con la política, existe estabilidad y consistencia a lo largo del tiempo con relación a las bases culturales relativas a la política. En cambio, la opinión pública se refiere a opiniones puntuales de los ciudadanos sobre las acciones o decisiones de los responsables de las instituciones públicas. Entonces, una vez que la cultura política está asociada a la idea de estabilidad, la opinión pública se manifiesta en fenómenos de corto plazo, llegando a ser una parte sustancial de la realidad social.

Se puede, entonces, resumir de lo dicho hasta aquí que: 1) Los medios de comunicación, ejercen una forma de poder ideológico, que (intencionalmente o no) determinan los asuntos que son importantes tratar e indican, también, la forma como ellos deben ser pensados y debatidos, 2) Los medios de comunicación son un elemento esencial para la conformación de la opinión pública, 3) La opinión pública se manifiesta en fenómenos de corto plazo y se refiere a opiniones puntuales de los ciudadanos sobre las acciones o decisiones de los responsables de las instituciones públicas, 4) Resulta importante considerar que aquello que se dice en los medios de comunicación es más o menos falso y que es deseable adoptar una postura escéptica y crítica con relación a aquello que es dicho en esos medios.

En el caso específico de Argentina la relación: medios de comunicación/opinión pública y política presenta características propias que deben ser consideradas en este trabajo. El vínculo entre la política y los medios de comunicación pasó por varias etapas que se correspondieron con los cambios de gobiernos democráticos y de facto durante la historia argentina (REPOLL, 2010. p. 43-45).

Actualmente existe una clara disputa entre el gobierno y uno de los medios analizados en 
este estudio (Grupo Clarín). Esta relación conflictiva, si bien en un comienzo se alternaba entre el amor y el odio, se profundizó con la nueva ley de servicios audiovisuales sancionada en el año 2009 (ley 26.522). En los titulares del diario Clarín se identifican discursos que demuestran una clara oposición y un manifiesto enfrentamiento del Grupo Clarín con relación al gobierno (REPOLL, 2010, p.51).

Desde el gobierno existe, también, una reacción a estas críticas que puede ser deducida de diferentes discursos por parte de la presidenta Cristina Kirchner en donde se acusa al grupo económico de mentir y de desinformar. Conjuntamente, fueron tomadas algunas medidas que poseen elementos que hacen sospechar que éstas fueron implementadas como una forma de una ofensiva directa contra el Grupo Clarín y que no se trata de medidas objetivas y necesarias de gobierno, como lo son, por ejemplo: el bloqueo de representantes del sindicato de camioneros a la planta de impresión y distribución de los diarios; la estatización del fútbol, cuya transmisión se encontraba, antes de la estatización, en manos del grupo; las agresiones contra instalaciones e intimidaciones a directivos del grupo; la inspección fiscal al Grupo. El 10 de septiembre de 2009, entre 180 y 200 inspectores de la Administración Federal de Ingresos Públicos (AFIP) montó un operativo en Clarín; el intento del gobierno de controlar la empresa Papel Prensa (hasta el momento controlada por Grupo Clarín y Diario La Nación, con una minoritaria participación accionaria del Estado); y, finalmente, la promulgación de la ley de servicios audiovisuales (o ley de medios) (REPOLL, 2010, p.53).

Con relación a la ley de medios, los objetivos centrales de la misma dicen ser la promoción, desconcentración y fomento de la competencia con fines de abaratamiento, democratización y universalización de los servicios audiovisuales. La mayor crítica de la ley a las prácticas monopólicas y oligopólicas en la propiedad de los medios de comunicación es que ellas afectan seriamente la libertad de expresión y el derecho de información de los ciudadanos de los Estados miembros, y no son compatibles con el ejercicio del derecho a la libertad de expresión en una sociedad democrática. Dependiendo de cuál sea la composición y presencia geográfica de cada medio, éstos se ven afectados en mayor o menor medida por esta restricción. El Grupo Clarín es el medio de comunicación más afectado, pues es el más importante del país, que deberá transferir o vender de 150 a 200 licencias, además de los edificios y equipamientos donde están sus emisoras. Esto fue confirmado por la Corte Suprema Argentina que en 2013, luego de un pedido de inconstitucionalidad de algunos artículos de la ley por parte del grupo, la Corte la declaró constitucional (SILVA MARQUES; SILVA DE OLIVEIRA, 2015, p.7).

\section{El debate sobre la dimensión parlamentaria en el MERCOSUR y en Argenti- na: análisis jurídico-institucional}

En este apartado hacer una breve mención a la dimensión jurídico-institucional del Parlasur. Como fue mencionado en la introducción, serán tomadas como fuentes primarias para el análisis los diferentes documentos normativos: como Tratados, Protocolos y decisiones judiciales. Además de esas fuentes primarias, se contará con el auxilio de algunas fuentes secundarias, entre ellas, diferentes publicaciones doctrinarias que ayudarán a interpretar aquellos documentos.

A pesar de la intensificación del debate en los medios de comunicación y de las noticias relativas a la dimensión parlamentaria del MERCOSUR y, específicamente del Parlasur, a partir de la sanción de la ley 27.120 (que será estudiado en el punto que sigue), debe decirse que los asuntos relativos a la creación y funcionamiento de ese órgano y de la representación ciudadana no pueden 
considerarse una novedad en términos de coyuntura político-institucional y jurídica tanto desde la perspectiva regional, como de la nacional. En otras palabras, antes de que los medios de comunicación comenzaran a intensificar el debate sobre el Parlasur, las discusiones sobre las cuestiones parlamentarias, en general, y sobre el Parlasur, en particular, ya habían comenzado hacía algunos años dentro del MERCOSUR y en el plano interno, como se verá a seguir.

\subsection{El debate jurídico-institucional en el plano regional}

En el plano regional, la dimensión parlamentaria encontró su "germen" en el Tratado de Asunción (que dio nacimiento al Mercado Común del Sur "MERCOSUR”). Ese origen puede considerarse primitivo, pues el Tratado dedicó solo un artículo a la creación de un órgano de representación de los Parlamentos nacionales y de representatividad democrática, la llamada Comisión Parlamentaria Conjunta (CPC). En el año 1991, en la II reunión parlamentaria en Buenos Aires, se planteó la necesidad de crear un Parlamento del MERCOSUR. Se establece, en esa reunión, sin embargo, la Comisión Parlamentaria Conjunta prevista en el Art. 24 del Tratado de Asunción. En las declaraciones de este documento se puede leer claramente que existía una necesidad de institucionalizar la voluntad política de los Parlamentos de los cuatro miembros plenos del bloque, en el sentido de participar activamente del proceso de integración, pero no se hacía referencia a la representación directa de los ciudadanos.

En los años que siguieron las iniciativas de crear un Parlamento fueron perdiendo fuerza en el mismo momento en que el bloque se encontraba con un leve declive. Este freno puede atribuírsele a la situación política e ideológica de los años noventa. Los presidentes de la época, Carlos Saúl Menem (Argentina) y Fernando Collor de Mello (Brasil), sumidos en políticas neoliberales, tenían una concepción de la institucionalidad centrada en lo intergubernamental y, primordialmente, comercial. Con la suscripción del Protocolo de Ouro Preto en 1994 (POP), se incorporó a la CPC como órgano dentro de la estructura MERCOSUR, pero excluyéndola de los órganos con capacidad decisoria. Los años siguientes mostraron un estancamiento en los avances para la creación del Parlamento regional, que correspondió a la paralización general padecida en el bloque en su conjunto.

A partir del año 2000, recordado como el año del relanzamiento del bloque, puede observarse la aparición de propuestas presentadas por Argentina y Brasil, con la finalidad de constituir el Parlamento. En este marco se lleva a cabo la XV Reunión Plenaria en Santa Fe, de la CPC, en donde se aprobó la disposición 10/oo (Agenda para la institucionalización del parlamento MERCOSUR) pero que quedaron en meras conversaciones sin resultados fructíferos. Este estancamiento es provocado, entre otras cosas, por la profunda crisis que atravesó la Argentina en el año 2001, en donde la falta de legitimidad del gobierno de turno, al grito de: “...que se vayan todos...” provocaba un quiebre dentro de la estructura institucional interna del Estado.

El cambio en los gobiernos, a partir de 2002, de los dos socios más importantes del bloque, propició el escenario para un avance hacia la conformación del Parlamento. Así fue que en el año 2003, cuando los presidentes de Brasil, Luiz Inácio Lula da Silva, y Argentina Néstor Kirchner, recién electos, junto con el presidente de la Comisión de Representantes Permanentes (CPRM), Eduardo Duhalde, se pronunciaron a favor de la creación del Parlamento e impulsaron la idea para su concreción definitiva. 
Por medio de la Decisión CMC No 49/04 se manifestó la voluntad política de los presidentes de los Estados Parte de conformar el Parlamento antes del 31 de diciembre de 2006, dejando a la CPC la calidad de comisión preparatoria para realizar todas las acciones que fueran necesarias para su instalación. El acuerdo político que posibilitó la tarea fue una Reunión Plenaria Extraordinaria de la CPC, en octubre de 2005, en Buenos Aires, que como resultado de todas esas gestiones elevaron al CMC, para su aprobación, el proyecto que luego de algunas sugerencias realizadas por las cancillerías, fuera aprobado en la Cumbre de Montevideo de 2005, por Decisión CMC No23/05. Finalmente, el Parlamento del MERCOSUR fue constituido el 6 de diciembre de 2006, como sustituto de la Comisión Parlamentaria Conjunta.

Una vez constituido el Parlamento se iniciaron los debates para establecer el criterio de representación ciudadana. Esto es, establecer los parámetros cuantitativos y geográficos sobre los cuales los ciudadanos debían verse representados. Luego de varios debates sobre el tema se llegó a una solución mediante un acuerdo político que fue aprobado por Decisión del CMC en la VIII Reunión Extraordinaria del Consejo del Mercado Común el 18 de octubre de 2010.

Una de las cuestiones importantes relacionadas con la representatividad es la obligación del elecciones directas que surge del Protocolo en su artículo 6 que establece los parlamentarios deben ser elegidos por los ciudadanos de los respectivos Estados-partes, a través de sufragio directo, universal y secreto, inclusive determina que, a propuesta del Parlamento, el Consejo del Mercado Común debe instituir el "Día del MERCOSUR Ciudadano", para la elección de los parlamentarios, de forma simultánea en todos los Estados Partes. A su vez, se estableció que el mecanismo de elección de los Parlamentarios se regiría por lo previsto en la legislación de cada Estado-parte, la cual deberá procurar asegurar una adecuada representación por género, etnias y regiones según las realidades de cada Estado.

El plazo para la implementación de las elecciones directas dentro de los Estados-partes vencía en el año 2014 y se estableció en el Protocolo que a partir de la segunda etapa de transición que estaba prevista entre el primero de enero de 2011 y el 31 de diciembre de 2014 todos los parlamentarios debían ser elegidos directamente. Sin embargo, por recomendación 03/13 del Parlamento del Mercosur aprobada por decisión del Consejo de Mercado Comín (CMC) n n 11/14 se prorrogó el plazo hasta 2020. De los 5 Estados-partes del Mercosur, quienes han implementado la elección directa fueron, Paraguay y, recientemente, Argentina.

Como se puede observar de la descripción hecha hasta aquí sobre los diferentes hechos acontecidos desde la firma del Tratado de Asunción, la cuestión parlamentaria, a pesar de estar mencionada de forma breve y simple, siempre estuvo presente desde los inicios del proceso de integración.

\subsection{El debate jurídico-institucional en el ámbito nacional}

Como se sostuvo más arriba, las cuestiones referentes al Parlamento del MERCOSUR no sólo fueron debatidas a nivel regional, sino también, en el ámbito interno. Es así que, una vez que el Protocolo constitutivo del Parlamento es aprobado en ámbito regional, el mismo debe pasar por los parlamentos nacionales para su aprobación. Esto ocurrió en Argentina rápidamente, convirtiéndose en ley el día 27 de septiembre del año 2006. 
Como fue mencionado, también, en el ámbito regional ya estaban resueltas dos cuestiones fundamentales, la obligatoriedad de las elecciones directas y el criterio de proporcionalidad adoptado para la representación ciudadana. Restaba ahora que se establecieran los mecanismos para efectuarse las elecciones directas al interior de los Estados. En Argentina existieron, en el año 2010, algunas iniciativas que presentaban ciertas diferencias fundamentales entre ellas. Uno de los proyectos determinaba que la única alternativa viable para posibilitar la elección de Parlamentarios del MERCOSUR en tiempo oportuno y conciliando los dos principios que gobiernan la cuestión (el de representación ciudadana y el de representación de las unidades geográficas internas), era la elección por lista en distrito único. Otro de los proyectos sostenía que, siendo Argentina un país federal debe corresponder a cada una de las provincias argentinas una representación igualitaria ante el futuro Parlamento del MERCOSUR de acuerdo a una fórmula de elección que asegurara a las 23 provincias argentinas y a la Ciudad de Buenos Aires una representación igualitaria sin importar el número de Parlamentarios a elegirse, que podía ser variable con el tiempo en función de los índices de población que marquen su número, de acuerdo a lo que se estableciera en el Acuerdo Político para la Consolidación del Parlamento del MERCOSUR. El tercero de los proyectos proponía adoptar un criterio mixto. Se planteaba, entonces, la necesidad de que los parlamentarios del MERCOSUR se eligieran por un sistema mixto en el cual 24 parlamentarios serían elegidos de forma regional (un parlamentario por cada una de las 23 provincias y un parlamentario por la Ciudad Autónoma de Buenos Aires) y el resto de los cargos a cubrir serían elegidos de forma general (tomando al territorio Nacional como distrito único). Todos esos proyectos de ley perdieron estado parlamentario, al no haber registrado avances en dos años legislativos. Es así que, en el año 2014 se presenta un nuevo proyecto de ley por parte del Diputado del partido del actual gobierno Frente para la Victoria, Jorge Alberto Landau, quien retoma la propuesta de sistema mixto. Finalmente, ese proyecto se transforma en ley 27.120 el día 29 de diciembre de 2014, modificando el Código Electoral Nacional que, en el ámbito interno, también suscitó controversias al respecto de la constitucionalidad sobre un artículo específico.

\section{El debate sobre la dimensión parlamentaria del MERCOSUR en los medios de comunicación: Clarín y Página12}

En este apartado serán desarrollados los argumentos centrales expuestos en dos de los principales periódicos de Argentina vinculados a la dimensión parlamentaria del MERCOSUR, especialmente, con relación al Parlasur y las elecciones directas establecidas por la ley 27.120.

La metodología utilizada es el análisis lingüístico y crítico del discurso de esos dos medios, enfocándose, especialmente, en los debates que se iniciaron con el envío del proyecto de ley que instituye las elecciones directas en fines de 2014. Se intentará, así, decodificar el discurso emitido por estos dos medios y realizar una cronología discursiva de ambos. A su vez, se realizará una comparación entre los dos discursos para descubrir la existencia o no de diferencias fundamentales entre ambos medios de comunicación. El periodo analizado abarca desde la creación del Parlasur en 2006 hasta las elecciones Primarias Abiertas Simultáneas y Obligatorias (PASO) del 9 de agosto de 2015 .

\subsection{Clarín}

Desde el discurso elaborado por este medio de comunicación se podía observar, en los primeros tiempos que siguieron a la creación del Parlasur, una expectativa por su funcionamiento 
que quedó plasmada por la manifestación del desafío que significaba que el MERCOSUR pasara de los acuerdos comerciales y económicos entre gobiernos a una integración plena a los moldes de la Unión Europea. En este sentido se sostenía: “... el Parlamento que hoy comienza a gestarse tendrá el poder de dar señales políticas propias. No sólo a los Gobiernos-socios; también, al resto del mundo, que ya no sólo verá la foto de los Presidentes sudamericanos sino también de sus legisladores". Por su parte se argumentaba, también, que el Parlamento del MERCOSUR significaba un incentivo para el proceso de integración regional, siendo una semilla de institución representativa de los pueblos.

No obstante aquella primera manifestación, al poco tiempo de la creación del Parlasur, ya se vislumbraban, desde el discurso de este medio, las primeras señales de desilusión con relación al funcionamiento y el futuro del órgano. A los seis meses de su creación se publicaba lo siguiente: "El Parlamento del Mercosur nació con las mejores intenciones, pero hasta ahora es una cáscara vacía que alguien debería llenar”. Días después se transmite otro mensaje con la misma línea argumentativa: "El pobre rendimiento del Parlamento del Mercosur puede tener un impacto contraproducente al mostrar que lejos de responder a la representación de las sociedades de los países del bloque, se trata apenas de una estructura burocrática más, destinada a abultar en los presupuestos nacionales. La baja actividad del Parlamento del Mercosur evidencia las dificultades que atraviesa el bloque para cumplir con uno de los propósitos de la integración: el de avanzar en la creación de instituciones supranacionales".

Desde la creación del Parlasur hasta la sanción de ley 27.120 no hubo gran cantidad de noticias dedicadas a la cuestión parlamentaria del bloque. Durante ese periodo solo fueron informados, fundamentalmente, los sucesos más relevantes, como por ejemplo, la definición del criterio de proporcionalidad que se adoptaría para la representación dentro del Parlamento y algunas notas de opinión de estudiosos de la integración regional como la de Andrés Malamud quien, al tiempo que reconocía que el Mercosur resultó esencial para consolidar la democracia y garantizar la modernización económica, también sostenía que aquello que había sido un éxito, ya no lo es. Así era expuesto: "Definitivamente, el Mercosur fue un éxito. La palabra clave es "fue".

A partir del envío del proyecto de ley para la elección directa de parlamentarios al Parlasur en 2014, como fue adelantado, se intensificaron las notas sobre los acontecimientos relativos a esa cuestión. Es así que el primer análisis que se hizo desde este medio informativo fue, al exponer la opinión del ala opositora al gobierno actual, argumentar que podría existir una intención, mediante el envío del proyecto de ley, de esconder la intención de candidatear a la actual presidente, Cristina Fernández, para que integrara el Parlasur. Se decía, entonces, lo siguiente: "No obstante, en la oposición también advierten, con razonable recelo, que los cambios impulsados por el texto presentado por Landau pueden significar un "Caballo de Troya” para, una vez legitimado el inicio de la discusión sobre el tema, luego incorporar la elección de parlamentarios del Mercosur en forma simultánea con los comicios nacionales".

Una vez instalada la idea de una posible candidatura, lo siguiente fue argumentar que los motivos para llevarla a cabo serían la búsqueda de fueros parlamentarios para que la presidente no fuera investigada por posibles actos de corrupción durante su gobierno, una vez finalizado su mandato. La noticia sobre los fueros y los motivos ocultos para el envío del proyecto de ley se extendió durante varios días en este periódico. En este sentido, una vez más se hace mención a los dichos de la oposición al gobierno diciendo que: "Uno de los diputados del Mercosur, Claudio Lozano (Un- 
idad Popular), cree que se está forzando una elección para beneficiar a una sola persona cuando todavía no se sabe qué función cumple el organismo para el que se la quiere postular. De hecho, desde que empezó a funcionar en Montevideo, en 2007, el Parlasur carece de carácter resolutivo y sólo puede emitir recomendaciones al Consejo del Mercado Común, que integran cancilleres y ministros de Economía de los cinco países que componen el foro. Un Parlamento que no puede emitir leyes es toda una contradicción. Otra representante, la senadora radical Laura Montero, cree que las restricciones comerciales de la Argentina "son la principal causa de la decepción" que atribuye a la demora en completar el Parlasur".

A pesar de que la mayor cantidad de notas se dedicaron a exponer las opiniones de los opositores al gobierno, no se puede dejar de mencionar que hubieron algunas pocas noticias que también presentaron algunos argumentos oficialistas y, una vez confirmado el hecho de que la actual presidente no sería candidata al Parlasur y, con ello, desmentidas las especulaciones de la oposición, el discurso del medio informativo se dirigió, especialmente, a criticar la funcionalidad y relevancia del Parlasur. También fue presentado como polémico el fallo denegatorio del pedido de inconstitucionalidad de Gerardo Fabián Milman, presidente del partido GEN, al cual se hizo mención en el punto anterior.

Así, el Parlasur fue categorizado como una estructura cara y sin impacto para los países. Fue mencionado que, pese a que recién los parlamentarios comenzarán a trabajar oficialmente en 2020 (discurso que se propagó durante varios días), cobrarán salarios desde ahora y eso implicaría un gasto innecesario. En otra nota se mencionaba el proyecto de ley presentado por un diputado de Partido Demócrata de Mendoza, quien solicitaba que los parlamentarios que fueran electos sólo cobraran viáticos hasta 2020, cuando el foro regional entrará en vigencia plena.

Por último, resta indicar en este análisis argumentativo cronológico, que las últimas noticias vertidas sobre el tema fueron dirigidas en el sentido de colocar en cuestión la compatibilidad de las elecciones directas en Argentina, con la cantidad de parlamentarios brasileños. En otros términos, lo que se cuestionaba era el hecho de que Argentina contaría con más parlamentarios que Brasil y eso provocaría un desequilibrio. De esta forma se resumía la cuestión: "Ocurre que, en una situación inédita e insólita, Argentina tendrá hasta 2019 más legisladores del Mercosur que Brasil, un desequilibrio que surge del hecho de que el kirchnerismo logró imponer en los comicios generales de octubre la elección directa de los parlamentarios del bloque. Negri es, hasta diciembre, parlamentario del Mercosur elegido por la vieja vía, indirecta, y no rentada a diferencia de los que asumirán el próximo 14 de diciembre que empezarán a cobrar lo mismo que un diputado nacionales, alrededor de $\$ 70000$ mensuales".

\subsection{Págína 12}

Durante el periodo que va desde la creación del Parlamento regional hasta la sanción de la ley 27.120 existieron varias notas que retrataron las diferentes actividades desarrolladas por el Parlasur. Las noticias dedicadas al Parlasur incrementaron de forma considerable a partir del envío del Proyecto de Ley al Congreso que propuso las elecciones directas de parlasurinos en 2014. No obstante este hecho, no se puede dejar de mencionar que el asunto relativo a las elecciones directas fue mencionado en algunas notas con anterioridad en este periódico. Así, por ejemplo, en nota publicada en diciembre de 2009 ya se adelantaba, citando a Florisvaldo Fier "Doctor Rosinha" que: "Para 2014 debería haber elecciones directas en todos los países. Los partidos políticos deben 
moverse hacia la integración, por lo tanto hay que dejar de lado las visiones personales y tener una mirada regional. Estamos librando la batalla de la supranacionalidad". A su vez, se le daba una importancia a las elecciones directas puesto que se decía que una vez que ellas se produjeran podrían modificarse las atribuciones del parlamento para que éste pueda tener un mayor peso en la sociedad y dentro del propio bloque. En ese sentido se sostenía que: "Las decisiones que por ahora toma esta institución política del Mercosur no son vinculantes, por lo tanto no tienen un efecto directo sobre la ciudadanía. Sin embargo, los parlamentarios apuestan a que una vez que se produzcan las elecciones directas puedan modificarse las atribuciones del parlamento para tener un mayor peso en la sociedad y dentro del propio bloque".

También en el año 2010 ya se anticipaba la necesidad de una modificación de la ley electoral para garantizar las elecciones de parlamentarios regionales. Se informaba la voluntad del ala oficialista del gobierno en el Congreso Nacional de realizar tal modificación para las elecciones presidenciales del año 2011. Se mencionaba entonces que: "Uno de los apuros de West es que para implementar una elección que tenga a todo el país como distrito único debe coincidir con una elección presidencial. Si no se lograra en 2011, la elección de los parlamentarios del Mercosur quedaría postergada para 2015 ".

Desde el 2011 hasta fines de 2014 no fueron encontradas noticias relevantes sobre la cuestión parlamentaria del Mercosur hasta que fue enviado el nuevo proyecto de ley que promovía la elección directa de parlamentarios al Congreso. El tema de las elecciones directas fue abordado por el periódico mostrando tanto las posturas del oficialismo, como también, las de la oposición. Del lado oficialista se sostuvo, citando al diputado Landau, quien había presentado el nuevo proyecto de ley, que la modificación del código se realizaba en un año no electoral, precisamente, para intentar evitar conjeturas con relación a intereses relacionado a la coyuntura política. Del lado opositor se mencionaron las posturas del diputado por el Partido Radical Mario Negri, quien consideró que la votación de representantes del Mercosur se tendría que realizar simultáneamente en todos los países miembros "porque en caso contrario se puede dar la paradoja de que Argentina tenga más representantes que Brasil", las del diputado Pablo Tonelli del Partido PRO y del diputado Claudio Lozano del Bloque Unidad Popular y Parlamentario, quienes sostuvieron que había un problema de oportunidad por considerar que la elección debía fijarse cuando existiera un acuerdo político con el resto de los países y, finalmente, la de Adrián Pérez por el Frente Renovador, quien consideró la falta de funcionalidad y competencias del Parlasur.

Posteriormente, la noticia sobre la reforma de la ley electoral fue colocada en términos de: "un lío para la oposición". Se sostenía, entonces, que: "Luego de rechazar el dictamen del kirchnerismo bajo la sospecha de que se trataría de "una maniobra electoral" para llevar a Cristina Fernández como candidata al Parlasur en las boletas del oficialismo, desde distintos sectores del abanico opositor creyeron encontrar una oportunidad para unificar candidaturas contra el Gobierno. Pero la idea de presentar una lista opositora común al Parlamento regional, fogoneada desde distintos lugares, comenzó a complicarse". Esa noticia volvió a repetirse días después, pero a ella se le sumaron los dichos del oficialismo en palabras del diputado Guillermo Carmona quien dijo a este medio que las inmunidades a parlamentarios del MERCOSUR son las mismas que las establecidas para los parlamentarios nacionales y que los parlamentarios asumirían de forma inmediata. Todos estos datos fueron colocados para rebatir los argumentos de la oposición. También fueron colocados los argumentos del Senador oficialista Miguel Ángel Pichetto quien dijo que: "Si alguien buscara inmunidades se buscarían más en el marco de la Constitución nacional y no en una ley". 
Finalmente, con la frase: "un voto por la integración" fue lanzada la noticia sobre la aprobación por la Cámara de Diputados y más tarde la aprobación de la ley por la Cámara de Senadores de la ley que instituya las elecciones directas.

Una vez sancionada la ley, Página12 comenzó a enfocar su atención a las voces del oficialismo. Los argumentos vertidos se basaron en tres elementos básicos. En primer lugar, fue una defensa a la propia a la ley. En segundo lugar se resaltó la importancia del Parlasur y a la integración latinoamericana y, en tercer lugar, se apuntó a ciertos errores en los que incurrían algunos sectores de los medios de comunicación.

Con relación a la primera cuestión se argumentaba que: "acusar al kirchnerismo de sancionar la elección de los representantes para el Parlasur con el solo fin de "inventarle" un cargo a Cristina Kirchner "es minimizar enormemente la discusión" sobre la importancia del cuerpo regional. "Cualquier encuesta muestra que la Presidenta es la dirigente con mayor caudal individual electoral. Podría ser candidata a diputada en la provincia de Buenos Aires, no tendría por qué inventarse un cargo para ella”. Además fueron expuestos los dichos del ex canciller y candidato a parlamentario Jorge Taiana, quien según los que consta en el periódico aseguró que: "ser elegidos por el voto popular les da a los integrantes de ese organismo del Mercosur "mayor legitimidad y mayor capacidad" para actuar en tareas que tienen que ver con los distintos aspectos de la integración”.

Con relación a la importancia del Parlasur y de la integración latinoamericana fueron expuestos principalmente, también, los argumentos de Jorge Taiana. Así, fue mencionado que: "El principal desafío que tenemos los parlamentarios del Mercosur es darle un nuevo impulso al proceso de integración, ayudar a remover la falta de información y los obstáculos, y favorecer el conocimiento entre los pueblos, porque nadie ama ni se involucra con lo que no conoce" o las consideraciones sobre "la integración como un proceso complejo, aduciendo que no hay integración sin una pata parlamentaria. Para Taiana el MERCOSUR: "No es un proceso de sólo integración económica sino también cultural, comunicacional. Es en todas las áreas: salud, educación, derechos humanos, donde debemos compatibilizar cosas".

Asimismo se argumentaba que: "No hay desarrollo sustentable sin integración regional, por eso los que queremos una Argentina con desarrollo, justicia social y con soberanía política queremos más integración. La autonomía entre iguales es la única forma de mantener nuestra autonomía y la defensa de la soberanía", agregó.

Con relación a lo económico fue mencionado que: "El Mercosur sigue siendo un actor comercial muy poderoso en el mundo, pero a partir de la crisis económica pasamos de un período de alto crecimiento a otro de desaceleración".

Asimismo, Tatiana considera que las elecciones de parlamentarios del MERCOSUR son una oportunidad importante para debatir qué MERCOSUR se quiere, se necesita y se debe construir.

El secretario de Asuntos Relativos a las Islas Malvinas de la Cancillería y candidato a parlamentario del Mercosur, Daniel Filmus, también fue otra de las personas a las cuáles este periódico le dio voz, una vez sancionada la ley de elecciones directas de parlamentarios. El candidato consideró que: "el triunfo del Frente para la Victoria encabezado por Daniel Scioli en la lista de candidatos para el Parlasur muestra el decidido apoyo de los argentinos al proceso de integración regional que se inició con la recuperación de la democracia en 1983 y hoy continúa como política de Estado. 
Este proceso, que se profundizó a partir del No al ALCA impulsado por Néstor Kirchner en Mar del Plata y del que se están cumpliendo diez años, es una de las claves para continuar con el proceso de desarrollo y reindustrialización que se lleva adelante desde el 2003 y hoy continúa liderando la presidenta Cristina Fernández de Kirchner".

También fueron mencionados los dichos del alto representante general del Mercosur, el brasileño Florisvaldo Fier (Dr. Rosinha), quien consideró que la decisión de la presidenta Cristina Fernández de Kirchner de impulsar la elección directa de representantes argentinos al Parlasur "es correcta, porque cumple con un acuerdo político constitutivo general y fortalece este órgano deliberativo en tiempos difíciles". Además señaló que "Los parlamentarios electos por Argentina representan al pueblo y no al Estado, y eso permite reducir el déficit institucional que existe en la actualidad en el Mercosur".

También fue comunicado que los parlamentarios asumirían en diciembre. Ese dato pretendió contradecir los argumentos de los otros medios que estaban comunicando que los parlamentarios sólo asumirían en 2020: "El Parlamento del Mercosur definió durante la sesión de ayer en Montevideo que los representantes argentinos que resulten electos en las elecciones del 25 de octubre asuman sus bancas en el organismo regional el próximo 14 de diciembre, desbaratando así la errónea y repetida versión de que no ocuparían sus escaños hasta 2020 ". "El organismo ya está funcionando pero con diputados seleccionados entre los legisladores nacionales".

\subsection{Análisis comparativo}

En el cuadro a seguir se ordenan las principales diferencias encontradas en el discurso elaborado por los dos periódicos:

\begin{tabular}{|c|c|c|c|c|c|c|}
\hline $\begin{array}{c}\text { Medio } \\
\text { analizado }\end{array}$ & $\begin{array}{c}\text { El Parlasur está } \\
\text { en funciones }\end{array}$ & $\begin{array}{c}\text { Los Parlamen- } \\
\text { tarios asumirán } \\
\text { en } 2020\end{array}$ & $\begin{array}{c}\text { Expone. Espe- } \\
\text { cialmente, los } \\
\text { argumentos de } \\
\text { la oposición }\end{array}$ & $\begin{array}{c}\text { Expone la } \\
\text { mayoría de los } \\
\text { argumentos, } \\
\text { dándole un } \\
\text { espacio mayor } \\
\text { al oficialismo }\end{array}$ & $\begin{array}{c}\text { Expone } \\
\text { argumentos } \\
\text { optimistas con } \\
\text { relación a la } \\
\text { integración y al } \\
\text { Parlasur }\end{array}$ & $\begin{array}{c}\text { Expuso el } \\
\text { debate sobre } \\
\text { las elecciones } \\
\text { directas antes } \\
\text { del año 2014 }\end{array}$ \\
\hline Clarín & No & Sí & No & No & No & No \\
\hline Página12 & Sí & No & No & Sí & Sí & Sí \\
\hline
\end{tabular}

Ambos periódicos mostraron una visión optimista y resaltaron la importancia del Parlasur como una herramienta para el progreso del proceso de integración al momento de su creación. No obstante, pocos meses después de la creación del órgano, el periódico Clarín cambia su postura inicial y comienza a elaborar un discurso crítico basado en la poca eficacia del mismo. Al contrario, las noticias en Página1 2 mostraban un Parlamento activo y exponía algunas de sus actividades durante el periodo 2007-2009.

Desde la creación del Parlasur hasta la sanción de ley 27.120 no hubo gran cantidad de noticias dedicadas a la dimensión parlamentaria del bloque en ninguno de los dos periódicos, pero mientras Clarín informaba ciertos sucesos relevantes, como por ejemplo, la definición del criterio de proporcionalidad que se adoptaría para la representación dentro del Parlamento y algunas notas de opinión de estudiosos de la integración regional como la de Andrés Malamud, que demostraban una postura descreída del MERCOSUR, en Página12 ya se abordaba la cuestión de 
las elecciones directas de los Parlamentarios y se exponían los principales proyectos de ley que trataban la cuestión.

Con el envío del proyecto de ley de elecciones directas en 2014 las noticias sobre el Parlasur aumentaron en términos cuantitativos en los dos periódicos. No obstante ese hecho, puede observarse que en Clarín fueron expuestos, en mayor medida, los argumentos de la oposición que se basaban en especulaciones sobre los reales intereses por detrás del proyecto de ley. Por su lado, en Página1 2 si bien en un comienzo eran expuestos todos los argumentos, tanto de la oposición como del oficialismo, en un momento posterior, tomaron relevancia las posturas oficialistas.

Desde el Clarín se argumentaba que el Parlasur no se encuentra en funciones y que los parlamentarios asumirían en 2020. Ambos dichos fueron desmentidos desde Página12.

\section{Consideraciones finales}

El objetivo central de este trabajo fue analizar, críticamente, la forma en que dos periódicos (Clarín y Página 12), presentaron la cuestión parlamentaria del MERCOSUR en Argentina. El debate sobre la importancia y funcionalidad del Parlasur se intensificó en los medios de comunicación del país con motivo del envío al Congreso Nacional del proyecto de ley que prevé las elecciones directas de parlamentarios mercosurinos.

Para conseguir alcanzar el objetivo propuesto se requirió el análisis de algunas cuestiones teóricas previas que hicieron referencia al papel que cumplen los medios de comunicación en la conformación de la opinión pública y la explicación de la relación entre los medios de comunicación y el actual gobierno en Argentina, con especial mención al Grupo Clarín. Además, se sostuvo que en el análisis de un órgano como el Parlasur, el estudio sobre las cuestiones jurídico-institucionales, no es suficiente. En este orden de ideas, se argumentó que el análisis jurídico-institucional sólo puede evidenciar aquello que es o que debería en términos jurídicos, pero no es suficiente para determinar la idea que los ciudadanos se forman sobre el órgano. Este último elemento se muestra como fundamental, pues el Parlasur es una institución creada recientemente y forma parte de un proceso de integración regional, el cual, si bien el ciudadano común conoce poco, la intención es imbuirlo de eficacia democrática. Quedó demostrado en este trabajo que:

- Los medios de comunicación cumplen un rol fundamental, ya que poseen gran responsabilidad al respecto de las ideas y percepciones que los ciudadanos se puedan crear, no sólo del órgano analizado en este trabajo, sino del MERCOSUR en su conjunto;

- Que el debate sobre las cuestiones parlamentarias había comenzado en el plano regional y en el plano interno, mucho antes que los medios de comunicación intensificaran las noticias, informaciones y debates sobre el Parlasur;

- La existencia de dos posturas e interpretaciones divergentes en los medios de comunicación analizados sobre un mismo fenómeno.

No obstante, la existencia de diferentes puntos de vista no puede ser considerada algo negativo o nocivo per se. De hecho, una de las condiciones democrática de la opinión pública es que esta sea "polífónica", es decir, que exista la posibilidad de creación y manifestación de diferentes 
opiniones contrapuestas.

Más allá de estos argumentos, lo que no resulta prudente ni razonable, es que los medios de comunicación distorsionen la realidad de un hecho concreto con el fin de sostener determinado argumento o defender determinada opinión política. En otras palabras, será necesario identificar los casos en que los medios de comunicación deforman aquello que existe para crear, mediante el discurso, una nueva realidad diferente de la anterior. Trabajos como el propuesto, se elaboran, entonces, con el fin de alertar sobre estas maniobras para que el ciudadano común pueda contar con mayores herramientas al momento de analizar y crearse la realidad.

En este orden de ideas, se concluye que existen cuestiones que son, indefectiblemente, datos objetivos de la realidad y que independen de los juicios de valor y de opiniones. En nuestro caso de análisis, estos datos provienen de la dimensión jurídico-institucional del Parlasur. Específicamente, existen dos cuestiones sobre las cuales, desde uno de los medios de comunicación analizados (Clarín), se proporcionaron datos que no se correspondían con la realidad jurídico-institucional del Parlasur (Parlamento que no está en funciones y parlamentarios asumirían en 2020).

El resto de las cuestiones analizadas sobre los medios de comunicación referentes al Parlasur, que no se corresponden con datos erróneos de la realidad, demuestra la existencia de, al menos, dos visiones de mundo: la visión de aquellos que no ven en la integración un camino hacia el perfeccionamiento de nuestra unión latinoamericana, factor que podría traer un mayor bienestar para nuestros pueblos, y aquellos que entienden lo contrario. Los primeros parecen contentarse en describir una realidad que juzgan inmutable y reprochan toda propuesta de profundización por creerla excesiva y superflua. Los últimos sostienen que la salida del círculo vicioso, que significa la no integración por la falta de existencia de ella, resulta de la profundización de sus elementos constitutivos. Una vez más el idealismo y el realismo se manifiestan como opuestos, dependerá de cada uno de nosotros poder concebir un término medio entre esos dos polos para no ser engañados con propuestas quiméricas, ni contentarnos con realidades mutables.

\section{Referencias bibliograficas}

CARPIZO, Jorge. Los medios de comunicación masiva y el estado de derecho, la democracia, la política y la ética. Boletín Mexicano de Derecho Comparado, nueva serie, año XXXII, núm. 96, septiembre-diciembre 1999

MAFFEI, Brenda Luciana. Mercosur y democracia: análisis desde una perspectiva amplia y estricta de la cuestión. En: SCOTTI, Luciana Beatriz (Directora). Balances y Perspectivas. A 20 años de la constitución del Mercosur. Buenos Aires: EUDEBA, 2013

MAFFEI, Brenda Luciana; ECHAIDE, Javier. El Parlamento del MERCOSUR. Aspectos amplios y estrictos de la cuestión democrática en el bloque. Buenos Aires: BdF, 2015

MANZANO, Vicente. Introducción al análisis del discurso. 2005. Disponible en: http:// www.aloj.us.es/vmanzano/docencia/.../discurso.pdf

MARQUES, Rodolfo Silva; OLIVEIRA, André Silva de. A Regulação da Mídia na América do Sul no período 2003-2015: análise comparada entre Brasil e Argentina. Anais do Seminário Internacional de Ciência Política Universidade Federal do Rio Grande do Sul. Porto Alegre. Set. 
2015. Disponible em: http://www.ufrgs.br/sicp/files/2015/o9/RodolfoMarquesAndr\%C3\%A9-Oliveira.pdf)

RAMOS, Hugo Daniel. Los partidos políticos argentinos y el MERCOSUR. Las bases político-partidarias de la integración regional (1991-2011) En: BOLOGNA, Alfredo Bruno. La política exterior de Cristina Fernández al finalizar su mandato. Rosario: UNR, 2014. p. 403-430

REPOLL, Jerónimo. Política y medios de comunicación en argentina. Kirchner, Clarín y la ley. Andamios. Volumen 7, número 14, septiembre-diciembre, 2010

RUBIO, José María Ferreres. Opinión pública y medios de comunicación. Teoría de la agenda setting. Gazeta de Antropología, 2009, 25 (1), artículo 01. Disponible en: http://hdl.handle. net/10481/6843).

RUSSELL, Bertrand. Ensaios céticos. Trad. Marisa Motta. Brasil: L\&PM pocket, 2014

URIARTE, Edurne. Introducción a la Ciencia Política. Madrid: Tecnos, 2002

\section{Referencias electrónicas}

Clarin.com. Disponível em: http://www.clarin.com/tema/parlasur.html. Acesso em: $2 / 11 / 2015$.

Pagina12.com.ar. Disponível em: www.pagina12.com.ar. Acesso em: 2/11/2015. 